\title{
ILUSTRACIÓN CATÓLICA Y ARGUMENTOS POLÍTICO-TEOLÓGICOS EN LA INDEPENDENCIA DE LA NUEVA GRANADA*
}

\author{
POR \\ MARÍA del RosARIO VÁZQUEZ PIÑEROS ${ }^{1}$ \\ Universidad de La Sabana
}

\section{RESUMEN}

Este artículo presenta un análisis de los argumentos político-teológicos que defendieron en la Nueva Granada, tanto quienes apoyaron la independencia de España, como quienes se mantuvieron fieles a la Corona. La investigación explica la importancia de dichos argumentos en este virreinato, como parte integral del contexto cultural hispánico al final del Antiguo Régimen; así como la marcada influencia de la llustración católica durante este período.

PALABRAS CLAVE: Nueva Granada; independencia; Iglesia; Ilustración católica; pensamiento político-teológico; jansenismo; neoescolástica; absolutismo; Derecho Divino.

\section{CATHOLIC ENLIGHTENMENT AND POLITICAL-THEOLOGICAL ARGUMENTS IN THE INDEPENDENCE OF NEW GRANADA}

\begin{abstract}
This article presents an analysis of the political and theological arguments they defended in New Granada, both those who supported the independence of Spain and those who remained faithful to the Crown. The research explains the importance of this type of subjects in the cultural context of this viceroyalty, as part of the Hispanic context at the end of the Old Regime; as well as the influence of the Catholic Enlightenment in the ideological sphere that marked this period.
\end{abstract}

KEY WORDS: New Granada; independence; Church; Catholic Enlightenment; political and theological thougth; jansenism; neoscholasticism; absolutism; Divine Law.

Cómo CITAR ESTE ARTículo / CitATION: Vázquez Piñeros, M.a R. 2019. «llustración católica y argumentos político-teológicos en la independencia de la Nueva Granada». Hispania Sacra 71, 143: 345-355. https://doi.org/10.3989/hs.2019.025

Recibido/Received 22-11-2017

Aceptado/Accepted 13-02-2018

\section{INTRODUCCIÓN}

El objetivo de este artículo es realizar un análisis del conjunto de argumentos político-teológicos presentes en la guerra de independencia en el virreinato de la Nueva Granada (1808-1819); y explicar su relación con el contexto cultural propio de la llustración católica, en el ámbito hispánico. Esta investigación tuvo en cuenta fuentes primarias que

* Este artículo forma parte del proyecto de investigación: La relación entre política y religión: un examen de la filosofía política desde la primera modernidad hasta la postmodernidad (HUM-48-2012), Facultad de Filosofía y Ciencias Humanas (Universidad de La Sabana). Entidad Financiadora: Universidad de La Sabana.

1 maria.vasquez@unisabana.edu.co / ORCID iD: https://orcid.org/0000-0002-7583-7695 se encuentran en el Archivo Histórico Cipriano Rodríguez Santa María ${ }^{2}$ y las Bibliotecas Nacional y Luis Ángel Arango. Algunas de dichos documentos pueden consultarse en ediciones impresas o digitales.

Entrar en materia conduce a recordar el importante papel de la religión a lo largo de la historia como elemento articulador de la cultura. En occidente, dicha influencia fue mucho más marcada en las sociedades tradicionales del Antiguo Régimen. De hecho, durante mucho tiempo

2 El Archivo Histórico Cipriano Rodríguez Santa María, conformado por los fondos Manuel María Mosquera y David Mejía Velilla, se encuentra abierto a los investigadores desde el año 2013, en la Biblioteca de la Universidad de La Sabana, Chía (Cundinamarca, Colombia). 
el catolicismo fue el elemento esencial de la identidad del pueblo español, lo que se hacía extensivo a los reinos de ultramar. Por consiguiente, tampoco es de extrañar el peso de la religión cuando los españoles europeos y americanos manifestaron su lealtad a la monarquía, tras la invasión napoleónica a la península ibérica, en 1808 , hecho que dio lugar a juramentos de fidelidad al rey cautivo, y, posteriormente, a la conformación de juntas de gobierno que reasumieron el poder en nombre del monarca. Finalmente, tales justificaciones político-teológicas fueron expuestas tanto por los americanos que creyeron legítima la ruptura con España, como por quienes optaron por mantenerse leales al Consejo de Regencia y a Fernando VII.

En este contexto, la rebelión y la lealtad a la monarquía fueron vistos como un problema de conciencia, y esto fue lo que condujo la discusión al plano político-teológico. ${ }^{3}$ Por lo tanto, podría hablarse de las revoluciones de independencia - de España frente a Napoleón, y luego de América respecto a España-, como de guerras político-religiosas. Así, en la independencia de Hispanoamérica se confrontaron la que podría denominarse una "teología de la revolución» y, por otro lado, una "teología del fidelismo». ${ }^{4}$ Cada una interpretó de forma distinta dos temas íntimamente relacionados: primero, en un plano general, la concepción del poder político; $y$, en segundo lugar, a nivel más específico, los aspectos de jurisdicción eclesiástica relativos a la forma como debía ser gobernada la Iglesia y a sus relaciones con el ámbito civil. Alrededor de estos dos temas esenciales giraron los principales debates político-teológicos de la independencia: la obligación de obediencia a los legítimos poderes civiles; el concepto de poder; el "gobierno según justicia»; la noción providencial de la historia y la «guerra justa»; la legitimidad de la intervención del Papa en los temas temporales y la autoridad de Roma frente a la monarquía y el episcopado.

\section{LA OBLIGACIÓN DE OBEDIENCIA A LOS LEGÍTIMOS PODERES CIVILES}

Es importante recordar que en el ámbito cristiano había un elemento que resultaba común: el origen religioso del poder y el consiguiente deber de obediencia a las autoridades temporales a partir de las recomendaciones del apóstol san Pablo a los romanos:

Hermanos, todos deben someterse a las autoridades constituidas, porque no hay autoridad que no provenga de Dios y las que existen han sido establecidas por Él. En consecuencia, el que resiste a la autoridad se opone al orden establecido por Dios, atrayendo sobre sí la condenación. ${ }^{5}$

No es de extrañar, entonces, que a lo largo del convulso ciclo revolucionario fuera recurrente la referencia a la mencionada cita, con el fin de insistir en la obligación de obediencia a los poderes civiles, primero frente al rey; y luego respecto a los nuevos gobiernos republicanos. Razón por la cual, el sacerdote realista José Antonio Torres y Peña, recordó a los santafereños las recomendaciones paulinas

3 Saranyana 2011: 230. Sobre el uso del concepto «teologías políticas» ver: Carvajal 2000: 335-351.

4 Ibídem: 234-235.

5 Carta de San Pablo a los Romanos 13: 1-10. de obediencia. ${ }^{6}$ Sin embargo, es importante anotar que este mismo tipo de exhortaciones las efectuó el clero independentista, al afirmar que el gobierno debía ser obedecido, eso sí, siempre y cuando fuera legítimo. ${ }^{7}$

Por otra parte, J. I. Saranyana explica cómo en este contexto salió a relucir la controvertida distinción entre pecado y delito, diferenciación que se hizo necesaria a raíz de las excomuniones promulgadas por la Inquisición contra los rebeldes patriotas. ${ }^{8}$ Para los realistas, ambos conceptos se identificaban; para los rebeldes, no. En el primer caso, si la Inquisición de Cartagena excomulgaba a los revolucionarios era porque la Iglesia jerárquica y prorrealista condenaba lo que consideraba como pecado, es decir, la desobediencia de los fieles al rey. ${ }^{9}$ En cambio, para los independentistas, una cosa era que la causa revolucionaria fuera obviamente sancionada por las autoridades civiles proespañolas, en cuanto era interpretada por ellas como un delito; y otra, muy distinta, que no fuera moralmente justa. De esta forma, el sacerdote patriota, oriundo de Popayán, Mariano del Campo y Larraondo cuestionó con clara ironía:

... ¿Porque sigo el Sistema Americano,

Soy Hereje, Blasfemo, un Hombre insano,

Cargado de desórdenes, y Vicios,

Y digno de los últimos Suplicios? ${ }^{10}$

\section{LAS CONCEPCIONES DEL PODER}

Bajo el ideario político del Antiguo Régimen, se esperaba del rey la búsqueda del bien común, la felicidad y la salvación de sus súbditos. ${ }^{11}$ Esto, aun cuando pudieran presentarse situaciones de descontento frente a ciertas medidas. En medio de esta difundida aceptación, es importante distinguir los planteamientos políticos vigentes a finales del siglo XVIII y principios del XIX, bajo la influencia de corrientes político-religiosas tan diversas, como el entonces retomado tomismo, la escolástica barroca, la llustración católica y el tardojansenismo, ${ }^{12}$ todas ellas conocidas en la Nueva Granada.

En primer lugar, es importante recordar que, en el siglo XII, el escolasticismo reasumió los presupuestos de la época clásica sobre el poder, basados en la concepción de la ley natural, reelaborados y precisados a partir de los aportes del cristianismo, por figuras como Manegold de Lautenbach, Juan de Salisbury y Santo Tomás de Aquino. La escolástica reconocía que, si bien el poder tenía origen religioso, era el pueblo quien lo delegaba en el rey; y, en caso de tiranía, tenía derecho a la resistencia. De acuerdo a Santo Tomás:

El régimen tiránico no es justo, ya que no se ordena al bien común, sino al bien particular de quien detenta el poder [...]. De ahí que la perturbación de ese régimen no tiene carácter de sedición, a no ser en el caso de que el régimen del tirano se vea alterado de una manera tan desordenada que la multitud tiranizada sufra mayor detrimento que con el régimen tiránico. ${ }^{13}$

\footnotetext{
6 Torres y Peña [1808]: 172-174.

7 Fernández de Sotomayor 1815.

8 Saranyana 2011: 231; Cortés 2010: 73-74.

9 Cortés 2010: 73.

10 Campo y Larraondo 2012: 117.

11 Silva 2005: 219.

12 Saranyana y Alejos Grau 2005: 29-35.

13 Tomás de Aquino 1960: 1089-1093.
} 
Luego, en la Edad Moderna, el absolutismo se legitimó con la teoría del Derecho Divino de los reyes, según la cual, la soberanía era cedida por Dios, no al pueblo, sino directamente al rey, quien no rendía cuentas a sus súbditos, sino ante la Providencia. Por lo tanto, aun cuando el gobierno de dicho monarca fuera tiránico, este no podía ser depuesto por su pueblo. En este orden, el rey era concebido como vicario de Dios en la tierra con un carácter divino:

Los Príncipes pues obran como Ministros de Dios, y sus Lugar-Tenientes en la tierra. [...] Por eso hemos visto que el Trono Real no es Trono del hombre, sino es Trono del mismo Dios. ${ }^{14}$

Para el teórico del absolutismo en el ámbito católico, J. B. Bossuet, Dios había sido el fundamento del vínculo social hasta que el pecado rompiera tal unidad; por lo tanto, solo la obediencia a su representante, el rey, podía mantener la cohesión; y por ende, la insubordinación era fuente de disolución y anarquía. ${ }^{15} \mathrm{~A}$ su vez, hay que recordar que en España, la llegada de la Casa de Borbón vino acompañada de cierta influencia teológica francesa, concretamente el Jansenismo, de corte galicano. ${ }^{16}$

La reacción frente al absolutismo surgió de la relectura de la concepción del poder heredada del medioevo, por parte de teólogos cristianos, entre quienes se destacaron los católicos neoescolásticos españoles del Siglo de Oro. En la lista de los más reconocidos de estos autores sobresalen los nombres de Francisco de Vitoria y posteriormente, el de Francisco Suárez, muy conocido en América. Para Vitoria, Dios era la fuente suprema del poder, entregado al pueblo, quien a su vez lo delegaba en el gobernante para que lo ejerciera con justicia: ese era el contrato. Si el monarca incumplía con dicho pacto, se convertía en un tirano y podía ser depuesto por sus súbditos:

Es verdad que, si el rey gobernase como un tirano, la república podría deponerlo, pues aunque la república le diera su autoridad, permanece en ella el derecho natural de defenderse; $y$, si no pudiera hacerlo de otro modo, puede rechazar al rey. ${ }^{17}$

Por su parte, Suárez no solo defendió las limitaciones al poder civil y el derecho de resistencia; también el tiranicidio y la guerra justa, a partir del casuismo, lo que le permitió establecer una variedad de matices sobre la realidad moral en la política. ${ }^{18}$ Sobre el derecho de resistencia, afirmó:

... si el rey su legítimo poder lo convirtiera en tiranía abusando de él en manifiesta ruina del Estado, el pueblo podría hacer uso de su poder natural de propia defensa, pues de éste nunca se privó. ${ }^{19}$

Es importante recordar que, a pesar de que los Borbones prohibieran la lectura de los neoescolásticos, el pensamiento de Suárez y el jesuitismo tuvieron permanencia en la sociedad americana, a través de los manuales empleados para la formación del clero. ${ }^{20}$

\footnotetext{
14 Bossuet 1789: 204 y 205.

15 Guerra 2012: 246.

16 Saranyana y Alejos Grau 2005: 35.

7 Vitoria 1995: 130.

8 Font 2013: 493-495.

9 Suárez 1970, Libro III, cap. 3, no. 2: 225.

Guerra 1992: 78.
}

En pleno siglo XVIII, la llegada de la llustración adquirió matices propios en la monarquía española, y, por ende, en el virreinato de la Nueva Granada, en donde se plasmaron dos comprensiones católicas del poder que se debatieron en la guerra de independencia: la absolutista (bajo la forma del despotismo ilustrado) y la liberal. Y al lado de ellas, tres formas distintas de relación entre la Iglesia y el ámbito civil, todas de tipo confesional: la primera, de corte regalista con el despotismo ilustrado. $Y$ en el marco liberal: un confesionalismo católico con separación de poderes, como el propuesto en las Constituciones durante la Patria Boba; ${ }^{21}$ y una forma sincrética de confesionalismo, acompañada de elementos tales como la libertad de cultos y un intento de sometimiento a la Iglesia similar al ejercido por los Borbones, pero ahora bajo el republicanismo, como, por ejemplo, durante la Gran Colombia. ${ }^{22}$

El despotismo ilustrado se afianzó sobre la teoría del Derecho Divino y supuso posiciones político-religiosas de corte regalista y galicano. Según este, el fin del Estado era el fomento del bien común y el progreso, a través del apoyo a la ciencia y la educación, bajo un criterio de utilidad; para lo cual se creía indispensable el ejercicio de un poder absoluto, por parte del monarca. Prosélito defensor de esta postura a fines del siglo XVIII, en la Nueva Granada, fue el capuchino español Joaquín de Finestrad, quien consideraba que el único límite cierto del poder era la moral cristiana. ${ }^{23} \mathrm{El}$ súbdito debía limitarse a "obedecer ciegamente». ${ }^{24}$ En resumen, propone Finestrad:

Los principios de nuestra Santa Religión nos persuaden que toda la potestad temporal proviene inmediatamente de Dios. Que la autoridad real es una participación de su soberanía. Que Dios colocó a los Reyes sobre la tierra, depositando en sus manos el Gobierno de sus Reinos, a quienes autoriza, como a nuestros padres, legítimos señores, Ilamándoles también nuestros Dioses. [...]. Por último nos persuade la Religión que quien resiste a los mandatos de los Reyes resiste a los del mismo Dios. ${ }^{25}$

En este orden de ideas, el concepto político de majestad o maiestas, da cuenta del atributo de esta superlativa potestad del monarca, y, por lo tanto, del deber moral y religioso de mantener la fidelidad y obediencia al rey. ${ }^{26}$ De acuerdo a dicha concepción, el rey era partícipe de la majestad divina. Por lo tanto, eran culpables del delito de lesa majestad quienes la «vulneran y ofenden», ${ }^{27}$ puesto que ella era «un reconocimiento que por derecho divino nace con los reyes». ${ }^{28}$

21 Etapa comprendida entre 1810 y 1815, caracterizada por las guerras civiles y luchas intestinas entre los neogranadinos, antes de la llegada del comandante español Pablo Morillo para castigar a los rebeldes revolucionarios, en el período conocido como la Pacificación (1815-1819).

22 Recibe el nombre de Gran Colombia (1819-1831), la República integrada por Colombia, Venezuela, Ecuador y Panamá, sancionada por la Constitución de Cúcuta de 1821, para diferenciarla de la República de Colombia, denominación recibida por el país con la Constitución de 1886.

23 Silva 2005: 219.

24 Finestrad 2001:186.

25 Ibídem: 233-234. La cursiva es nuestra.

26 Calderón y Thibaud 2010: 50.

27 Finestrad 2001: 176.

28 Ibídem: 177. Un episodio histórico, muy anterior, refleja la resistencia del pueblo español frente al absolutismo. Cuando la canciIlería flamenca de Carlos V quiso cambiar el tratamiento de Alteza por 
Otra postura, también católica, se identificó con algunos aspectos de la llustración liberal, tales como la división de poderes, el contractualismo y la soberanía popular. Sin embargo, se distanció del liberalismo, en aquellos puntos que lesionaban la tradición respecto a la idea sobre el origen divino del poder, las creencias religiosas y el estatus de la Iglesia frente al ámbito civil. Esta forma de Ilustración católica - en todo caso, nostálgica del pactismo y afín a la neoescolástica - no propuso un retorno a las antiguas formas representativas, pero sí un modelo liberal (con tres ramas del poder público), respetuoso del catolicismo y de la autonomía romana. Así, estos criollos recibieron de la Ilustración española el afán por el desarrollo científico y económico, no solo sin resentir su fe religiosa; ${ }^{29}$ sino de tal forma que sus propuestas políticas no riñeran con la herencia neoescolástica, ni tampoco con la ortodoxia en cuanto a la autoridad del romano pontífice.

Es así como en este contexto intelectual, el sacerdote caucano Mariano del Campo y Larraondo consideró al monarca español, absolutista y defensor de la teoría del Derecho Divino, como un "sátrapa inclemente». ${ }^{30}$ Dicha teoría terminaba por encumbrar al rey a un estatus pretendidamente divino, tal como había ocurrido en los tiempos del paganismo. Por eso, opinaba que este tipo de monarcas que "se adoran por deidades», conducían al dominio de la más "sangrienta Idolatría». ${ }^{31}$ Sobre estos excesos del absolutismo y la nostalgia de las antiguas tradiciones políticas, nos dice:

Y no adviertes también, que tus deidades,

Si quieres proceder con fe sincera,

Fueron algunas veces elegidas

En cortes, en comicios, y Asambleas? ${ }^{32}$

Mariano del Campo y Larraondo añoraba el pactismo del medioevo. Pero a la vez reconocía que el contrato social era parte inherente del pensamiento político tradicional católico; y que dicho pacto daba pie a la libre conformación de distintas formas de gobierno:

Todo, todo me anuncia, y me confirma,

A más de la razón, con evidencia:

Que hay contrato social, y siempre lo hubo

Y que Nación ninguna de la Tierra,

Jamás pierde al derecho de juntarse,

Y ordenar su Gobierno, como quiera. ${ }^{33}$

Por este camino, el sacerdote caucano no solo denunció la teoría del Derecho Divino y la tiranía del monarca español, sino que defendió el contrato social -en su concepción católica- así como el republicanismo, acudiendo para

el de Majestad, los toledanos consideraron esto como un exagerado enaltecimiento del monarca, puesto que "este título más convenía a Dios que a hombre terrenal» (Santa Cruz 1920-1925: 221, cit. por Fernández 2006: 117).

29 Jaramillo 1994: 78-79.

30 Campo y Larraondo 2012: 67.

31 Ibídem: 119 y 165.

32 Ibídem: 166. La cursiva es nuestra.

33 Ídem. Gaspar Melchor de Jovellanos, insigne representante de la Ilustración católica española, defendió el derecho de resistencia a la tiranía, en este caso de los invasores franceses, pero no desde el contrato social de Rousseau, sino desde Suárez y la neoescolástica (Gómez Hoyos 1962: 117). Sobre la llustración como heredera de la neoescolástica, ver: Uprimny 1952-1954. ello a ejemplos extraídos de la Historia Sagrada, ejercicio ya efectuado por otros autores como el neoescolástico Juan de Mariana. ${ }^{34}$

En este orden de ideas, las nuevas constituciones neogranadinas bajo la Patria Boba establecieron gobiernos que reglamentaron la igualdad ante la ley, la libre expresión y la soberanía del pueblo; mientras que simultáneamente proclamaron un abierto confesionalismo y la separación entre las dos potestades. Así, la Constitución de Cundinamarca de 1812, en su artículo primero, disponía que la Religión Católica era la única del Estado; y se comprometía a «defender con todo su poder las infalibles verdades que ella enseña dictadas por Dios». Pero, en todo caso añadía, acerca de la independencia de los dos ámbitos, el civil y el religioso:

La potestad civil no se entrometerá en materias eclesiásticas, ni la eclesiástica se mezclará en materias civiles; pero se auxiliarán mutuamente en sus casos, conforme a los sagrados cánones y a las leyes. ${ }^{35}$

Asimismo, la Constitución de Cartagena de junio de 1812, a la vez que hacía alusión a las ideas de la Ilustración y a las aspiraciones libertarias, invocaba a Dios, bajo cuya Providencia se encontraba «el derecho a existir, mantenernos y gobernarnos por nosotros mismos». ${ }^{36}$

Una tercera corriente - al principio minoritaria y con mayor aceptación entre los revolucionarios de segunda generación- fue aquella que resultó más cercana con la Ilustración francesa, aunque no llegara a implementar un anticlericalismo radical. Se trató, en realidad, de otra forma de liberalismo que, aunque confesaba el catolicismo de la nación y el deber del Estado de defender a la Iglesia, estaba abierto a la libertad de cultos; y su mayor interés en esta materia fue la instrumentalización de la religión para garantizar el nuevo orden social. Motivo por el cual buscó continuar con las políticas de los Borbones orientadas a someter a la Iglesia a lo que se consideraba como intereses superiores de utilidad pública. Por esa razón, no solo creyó conveniente recuperar el Patronato, sino implementar otro tipo de medidas que afectaron a la Iglesia. Esta postura eminentemente práctica fue la asumida por próceres como Bolívar y Santander, durante la Gran Colombia (1819-1830) —tras la Constitución de Cúcuta $^{37}-$, cuando, a pesar de la promulgación de la Constitución confesional de 1821, se dispuso la supresión de los conventos menores para el empleo de sus instalaciones como edificios destinados a la educación.

\section{EL «GOBIERNO SEGÚN JUSTICIA» ${ }^{38}$}

Es importante retomar un concepto esencial del pensamiento político-teológico cristiano del Antiguo Régimen: el "gobierno según justicia». La potestas, es decir, el permiso y licitud para el ejercicio práctico del poder, derivaba su legitimidad del carácter sagrado, en cuanto el rey era vicario de la potestas divina a través de una delegación directa, en el caso del absolutismo; o indirecta, según el acervo medieval y neoescolástico. Lo que en últimas significaba que, en

34 Mariana 1950: 471, cit. por Gómez 1962: 77-79.

35 Colegio Revisor y Electoral 1812: Título 1: Art 1. No. 2.

36 Olano 2014: 436.

37 Ibídem: 438.

38 Amores 2011: 131-152. 
cualquiera de los dos casos, un monarca justo debía gobernar de acuerdo con la ley de Dios, el Derecho Natural y para el bien común. Por consiguiente, no gobernar con justicia significaba caer en la tiranía y el despotismo, lo que, de acuerdo con la neoescolástica, podía conducir a la rebelión; o a la resignada aceptación, según la teoría del Derecho Divino, enseñada por los Borbones, durante el siglo XVIII.

Ahora bien, para los realistas, la independencia era injustificada, precisamente por motivos de justicia $-y$ no solo por razones de Derecho Divino- en cuanto que, para ellos, Fernando VII era un buen rey:

... un Rey que ha hecho su principal estudio en las Santas Escrituras, y que desde su entrada al Trono manifestó su piedad y celo por la religión, su amor al bien común y su compasión con los pobres. ${ }^{39}$

Para ellos, la revolución era la verdadera tirana -es decir, injusta-, por cuanto solo había traído guerra, desolación y caos. Así lo advirtió a los santafereños el sacerdote Antonio de León, en 1816, quien exaltó el gobierno monárquico por considerarlo «el único capaz de hacer felices a los Pueblos manteniendo los derechos de la justicia, de la tranquilidad y del buen orden $»{ }^{40}$ Por otro lado, para los realistas, tampoco era legítimo propiciar una rebelión puesto que, aunque existieran causas de descontento, la guerra podía empeorar unas circunstancias ya de por sí difíciles, como lo demostraban ante sus ojos las secuelas de este enfrentamiento durante la convulsa Patria Boba. Y recordemos que esta última razón no era privativa de los absolutistas; puesto que estaba de acuerdo con el pensamiento de Santo Tomás, cuando este rechazaba la rebelión, una vez que sus consecuencias conllevaran males peores que los de la tiranía.

Por otro lado, también en contra de la injusticia estaba el ya mencionado sacerdote independentista Mariano del Campo y Larraondo, quien con el fin de desmentir el peso de los argumentos religiosos de quienes se mantenían fieles a la corona, destacó la tiranía del gobierno español:

Ni pienses ya, que el celo

De nuestra religión os preste un velo:

Pues que inviolablemente

Severa, ella condena en toda Gente

El fraude, y la codicia.

La fuerza, la ambición, y la injusticia. ${ }^{41}$

Es decir que este miembro del clero ilustrado, católicoliberal y republicano, enseñó a los fieles que la rebelión contra la monarquía era legítima por razones de justicia; y porque estaba de acuerdo con algunas de las premisas más ortodoxas del pensamiento político-teológico del cristianismo medieval y neoescolástico.

\section{LA NOCIÓN PROVIDENCIAL DE LA HISTORIA Y LA «GUERRA} JUSTA»

Es preciso recordar que el cristianismo es una religión con un sentido eminentemente histórico en cuanto concibe la Historia de la Salvación como un elemento fundamental de su doctrina. Este recorrido tiene un principio, pero

\footnotetext{
39 Torres y Peña [1808]: 183.

40 León 1816.

41 Campo y Larraondo 2012: 79.
}

también anuncia un punto de llegada en el plano escatológico: el Juicio Final. Este sentido es elaborado por el pensamiento teológico de san Agustín en La Ciudad de Dios, ${ }^{42}$ donde plantea la lucha del reino espiritual, esto es, de la Iglesia frente al mal, contra la ciudad pagana o reino temporal, en el camino hacia la salvación, con el anuncio optimista del triunfo final de la Ciudad Celestial.

En esta concepción histórica existen tres actores o fuerzas protagónicas: Dios, el hombre y el diablo. Efectivamente, para Agustín, detrás del acontecer histórico está la Providencia. No obstante, ella no impone su voluntad al hombre, como ocurría con el hado en el ámbito de las culturas paganas de la Antigüedad, ${ }^{43}$ puesto que "Dios obra de un modo secreto y eficacísimo en el curso de la Historia». ${ }^{44}$ La aparición del mal se inicia con la división de los ángeles y la caída de muchos de ellos. Así, en el entramado de la historia surge ese tercer actor: el diablo. Es importante recordar que para Agustín, la historia es "pedagogía divina», pues el mal sirve para iluminar el bien, de tal forma que "las tinieblas hacen más bella y útil la luz». ${ }^{45} \mathrm{Y}$ aquí es necesario destacar la relevancia de la línea de continuidad o sentido de unidad de la concepción histórica agustiniana del pueblo de Dios, entre el Antiguo y el Nuevo Testamento. ${ }^{46}$

Así, lo anterior permite comprender la explicación que muchos católicos daban sobre los tiempos de guerra como los que vinieron tras la invasión napoleónica y la consecuente coyuntura revolucionaria. Se trataba de un castigo de Dios por los pecados de su pueblo: "La Providencia, pues, permite esos tiempos difíciles como una llamada a la conversión». ${ }^{47}$

Asimismo, este tipo de conciencia histórica permite entender la razón por la cual los sermones y pronunciamientos del clero solían tener tintes apocalípticos, en la medida en que el agitado período de finales del siglo XVIII y principios del XIX parecía evidenciar a los ojos de sus contemporáneos, un punto crucial de la lucha entre las «dos ciudades» y tal vez, para algunos, el inminente fin de los tiempos. Por otra parte, en un contexto sociocultural marcado por este tipo de concepción histórica, la defensa de una causa justa avalaba una "guerra justa», lo que a su vez implicaba que fuera entendida como "guerra santa»;48 y por eso, se esperaba contar en la batalla con el apoyo de la Providencia.

\footnotetext{
42 Artuñano 2010; Capánaga 1994: 234-259.

43 Ibídem: 236.

44 Ibídem: 237.

45 Ibídem: 241.

46 Ibídem: 243.

47 Ibídem: 166.
}

48 Vale la pena recordar el pensamiento que durante el medioevo justificó la idea de Cruzada y de los combatientes que participaban en ella, cuando de acuerdo a Bernardo de Claraval se creía que «... muriendo sirven a Cristo, y matando, Cristo mismo se les entrega como premio. Él acepta gustosamente como una venganza la muerte del enemigo y más gustosamente aún se da como consuelo al soldado que muere por su causa. Es decir, el soldado de Cristo mata con seguridad de conciencia y muere con mayor seguridad aún». Y continuaba: "Si sucumbe, él sale ganador; y si vence, Cristo. Por algo lleva la espada; es el agente de Dios, el ejecutor de su reprobación contra el delincuente. No peca como homicida, sino - diría yo- como malicida, el que mata al pecador para defender a los buenos. Es considerado como defensor de los cristianos y vengador de Cristo en los malhechores» (Bernardo de Claraval 2005: 45). La cursiva es de la editora. 
En el caso de la monarquía hispánica la concepción providencialista se vio especialmente reflejada en el autorreconocimiento como "reino católico por excelencia». ${ }^{49}$ En Nueva Granada, Torres y Peña explicó la forma en que desde los inicios de la Edad Moderna -tras la Reconquista, el descubrimiento de América, la lucha contra los infieles turcos y la herejía protestante- España ocupaba un lugar especial en la historia del cristianismo y en la defensa de la Iglesia. ${ }^{50}$ En este orden de ideas, Fernando VII representaba una monarquía que consuetudinariamente había protegido el catolicismo, y que ahora enfrentaba la irreligión de la Francia revolucionaria. ${ }^{51}$ Según Torres y Peña, la Providencia actuaría eficazmente a favor del pueblo español:

Pero vosotros sabéis que el Dios verdadero al que adoramos, es dueño absoluto de todos los tiempos y de los sucesos: y que no necesita de sacar las cosas del curso del orden regular para la ejecución de los designios más grandes de su providencia. No obstante [...] no podemos menos de confesar que la mano de Dios es la que obra y destruye todos los esfuerzos y ardides de los contrarios. ${ }^{52}$

Y de igual forma, este mismo sacerdote realista, a partir de su visión agustiniana de la historia, interpretó el sentido del sufrimiento en esta guerra:

Pero así son, Señores, regularmente los admirables juegos de una providencia inescrutable. A los más grandes personajes; a los que destina para las mayores empresas de sus glorias y para la felicidad de muchos pueblos, los alimenta desde el principio con el pan sólido de las tribulaciones más grandes. Así lo dispone entre los conflictos y las acechanzas, para que se formen con unos corazones fuertes, con un espíritu invencible, y se llenen de sentimientos de ternura y compasión hacia las calamidades de los miserables. ${ }^{53}$

Sin embargo, como contraparte, estuvieron quienes al abrazar la bandera de la independencia efectuaron alusiones similares, pero esta vez para equiparar a los republicanos con los israelitas, perseguidos por los egipcios, es decir, por los monárquicos fieles a España. ${ }^{54}$ Cuando Fray Diego Padilla elogió la Constitución de Cundinamarca de 1811, recordó que la independencia había tenido como principal objetivo que los neogranadinos sacudieran el yugo de la opresión; y «la defensa de la Religión, por la cual están resueltos a morir, deseando conservarla en toda su pureza». ${ }^{55}$

El sacerdote republicano, oriundo de la ciudad de Cartagena, Juan Fernández de Sotomayor, en el Catecismo o instrucción popular, afirmó que la guerra de independencia era «justa y santa, y acaso la más justa y más santa que se ha visto en el mundo de muchos siglos acá». ${ }^{56}$ Por su parte,

\footnotetext{
49 Torres y Peña [1808]: 178-179.

50 Ibídem: 176 y 177

51 Ibídem: 177.

52 Ibídem: 171-172.

53 Ibídem: 179 y 180.

54 Demélas-Bohy 2002: 143-164.

55 Padilla 1811: 1-20.
}

56 Fernández de Sotomayor 1820. Rosa María Martínez de Codes explica las razones que llevaron a Fernández de Sotomayor a redactar dicho catecismo: la influencia del clero realista en los sectores populares, que desembocaron en la rebelión de Tolú y San Benito contra el gobierno republicano de Cartagena, en 1812. Posteriormente, la Inquisición, que se trasladó de Cartagena a la realista ciudad de Santa Marta, declaró al prelado reo de alta traición (Martínez de Codes 1992: 93).
Mariano del Campo y Larraondo realizó analogías - de los patriotas con las diez tribus de Israel, oprimidas por las otras dos faltantes, representadas por España; y de los neogranadinos perseguidos en la etapa de la Reconquista por el comandante Morillo, con el pueblo de Judá57 -, en las que reflejó su concepción providencial de la historia, así como su convicción de que quienes luchaban del lado de la justicia -esto es, la independencia y la república ${ }^{58}$ - contarían con la protección divina, en el desarrollo del plan de Dios en las provincias americanas:

\section{Confiados en que el Padre Omnipotente \\ El triunfo nos dará gloriosamente, \\ Y libres, y felices viviremos. \\ Con una gratitud eterna, y pías. ${ }^{59}$}

Entonces, dada esta concepción providencial de la historia del pueblo de Dios, no es extraño que la invasión napoleónica desatara una prolífica citación de textos bíblicos en los que se establecieron analogías con la Historia Sagrada, ${ }^{60}$ para identificar la causa política propia -ya fuera de resistencia a la invasión napoleónica, de fidelidad a España o a favor de la emancipación - con la historia de la Iglesia y con las Escrituras. En palabras del presbítero Mariano del Campo y Larraondo:

Ya has visto, que podemos en Justicia Oponer nuestra fuerza a la Sevicia. Y qué tantos ejemplos la Escritura Nos proporciona en esta coyuntura. ${ }^{61}$

\section{LA DISCUSIÓN SOBRE LA AUTORIDAD DEL PAPA EN LOS TEMAS TEMPORALES}

La teoría teocrática que se consolidó en la Edad Media establecía que el romano pontífice, como vicario de Cristo, personificaba la máxima autoridad espiritual y temporal en la tierra para procurar la realización del principal fin del hombre, la salvación. Cuando un monarca no propiciaba dicho objetivo su autoridad se tornaba ilegítima y, por lo tanto, revocable. En este sentido, los gobiernos ejercidos por infieles eran igualmente ilegítimos y en consecuencia, el Papa podía entregarlo a los reyes cristianos. ${ }^{62}$ Lo anterior, sumado al hecho de que para 1492 la Iglesia no contaba con los recursos suficientes para la propagación de la fe en los territorios recién descubiertos, explica la razón de ser de la bula Inter caetera del 4 de mayo de 1493. En ella, el papa Alejandro VI les encargó a los Reyes Católicos la misión

57 Campo y Larraondo 2012: 123 y 126.

58 El episodio bíblico se refiere a la rebelión de diez de las doce tribus de Israel frente a la severidad del rey Roboam, hijo de Salomón (Arce 2012: 290).

59 Campo y Larraondo 2012: 69.

60 Guerra 2012: 231-287.

61 Campo y Larraondo 2012: 128

62 El derecho adjudicado a los pontífices para ceder las tierras de los infieles tiene su origen en la teoría medieval ostiense del cardenal Enrique de Susa, quien sostuvo en el siglo XIII que Cristo, como rey de reyes, había recibido los dominios de los pueblos, tanto en lo espiritual como en lo temporal; y que había heredado dicha jurisdicción a sus sucesores en la Santa Sede romana. Por lo tanto, el Papa tendría derecho de ceder a príncipes cristianos las tierras de los infieles (Ocampo 1999: 146). 
evangelizadora que se convirtió en el principal factor de legitimación del dominio español en América. ${ }^{63}$

Desde el siglo XVI, el análisis de este tema llevó a Francisco de Vitoria a proponer en su obra Relecciones sobre los indios y el derecho de guerra, ${ }^{64}$ los principios del Derecho de Gentes, la invalidez de los títulos de la monarquía española en este continente y la legitimidad del gobierno de los caciques sobre sus súbditos. En cuanto a las bulas alejandrinas, consideró que el Papa carecía del dominio civil o temporal en todo el orbe, pues él solo tenía potestad para las cosas espirituales. Tampoco las costumbres y los pecados de los pueblos indígenas justificaban la conquista española. No obstante, aceptaba como legítimos el derecho a predicar el Evangelio y a proteger el cristianismo y la jurisdicción del romano pontífice sobre los convertidos. Posturas similares fueron asumidas por los sacerdotes Antonio de Montesinos y Bartolomé de las Casas. ${ }^{65}$ Por otro lado, no hay que olvidar que en el siglo XVIII, fray Benito Jerónimo Feijoo, autor representativo de la llustración española, criticó la conquista de América; ${ }^{66}$ y que los postulados del tardo jansenismo (planteados en el Sínodo de Pistoya, de 1786), reducían la autoridad de la Iglesia a los asuntos estrictamente espirituales. ${ }^{67}$

Posteriormente, ya en la época de la independencia, el neogranadino Juan Fernández de Sotomayor hizo reflexiones similares. Criticó la crueldad de la conquista española de América y los procedimientos impositivos y sanguinarios de la cristianización; y en este orden de ideas, negó que las bulas alejandrinas y el compromiso de la corona con la propagación del Evangelio fueran razones válidas para legitimar su dominio:

No, porque el vicario de Jesucristo no puede dar ni ceder lo que no ha sido jamás suyo, mucho menos en calidad de Papa o sucesor de S. Pedro que no tiene autoridad ni dominio temporal, y el imperio que le fue confiado al mismo S. Pedro y que ha pasado a sus legítimos sucesores ha sido puramente espiritual, como se evidencia por las mismas palabras que contienen la plenitud del poder apostólico. ${ }^{68}$

De esta forma, vio en la independencia una solución moralmente válida; y en un sermón pronunciado en Santa $\mathrm{Fe}$, el 20 de julio de 1815, afirmó que había sido de "la silla Apostólica de quien se obtiene una bula que concede el dominio de América a sus primeros usurpadores $»{ }^{69}$ También el Precursor, Antonio Nariño, en su periódico La Bagatela, realizó el mismo cuestionamiento:

Y en qué página del Evangelio vemos que Jesucristo facultara a los Apóstoles para que regalaran imperios y autorizaran a los ambiciosos para que asesinaran a la especie humana? ${ }^{70}$

63 Hera 1992.

64 Vitoria 1928.

65 Ocampo 1999: 145.

66 Feijoo 1773: 257-262: «Tan trágica fue la conquista de la América, que hicieron nuestras Armas. A tanta costa se descubrieron sus Minas. No hay vena de oro, o plata en ellas, que no haya hecho verter arroyos de sangre de humanas venas». Sobre la crueldad de los Conquistadores agrega que «cebándose en Provincias, y Reinos, como en propios combustibles, a costa de ruinas granjean sus esplendores».

67 Saranyana 2010: 60.

68 Fernández de Sotomayor 1820.

69 Ibídem 1815

70 Nariño 1811, cit. por Ocampo 1999: 148.
Pero, también en este caso, el sacerdote realista Torres y Peña respondió a los anteriores argumentos. Criticó a los criollos proindependentistas - muchos de ellos descendientes de los conquistadores - por solo tener en cuenta las injusticias cometidas durante la conquista, mientras que «no confiesan jamás el derecho que los españoles adquirieron a su posesión, aunque son ellos los que la están gozando». De tal manera que, paradójicamente, quienes así se expresaban eran los mismos descendientes de los conquistadores, quienes «aglomeran delitos sobre las cabezas de sus padres y los ponderan aún más allá de lo que fueron». ${ }^{71}$ Asimismo, Torres y Peña consideró que el padre Las Casas había exagerado los excesos de la conquista; y que, al fin y al cabo, era más dura la tiranía que soportaban los indios por parte de sus caciques porque si antes eran tratados como esclavos, ahora lo eran como "hijos menores», bajo la tutela del gobierno español. Y subrayó el hecho de que la mayor parte de los agravios de los cuales los indios eran objeto, provenían no del gobierno español, sino de los mismos americanos y de los mestizos emparentados con ellos. Por último, lo más importante, era que todo debía «sacrificarse por la religión verdadera». Y así, si los indios habían perdido parte de sus libertades, esto se veía compensado por el bien recibido al entrar en el "gremio de la Iglesia». ${ }^{72}$

Una vez llegado el momento de la emancipación, el papado volvió a manifestarse a favor de España, encontrando un apoyo generalizado - aunque no absoluto- en el episcopado regalista americano, que en la práctica actuaba como parte del andamiaje del gobierno español en América. El mecanismo de presión para la obediencia al rey fueron la condena al pecado de rebelión y las excomuniones. Dicho apoyo puede explicarse en la medida en que la Santa Sede entendía los conatos revolucionarios americanos como una réplica del anticlericalismo francés, en todo caso peor que el regalismo de los Borbones. Por ello, en la encíclica Etsi longissimo, del 30 de enero de 1816, se realizó un llamado a la obediencia a las autoridades legítimas. La posterior elección de León XII (1823-1829) tuvo repercusiones contrarias a la causa patriota, puesto que dicho Papa resolvió brindar un firme respaldo a la monarquía, en momentos en que la independencia estaba prácticamente consolidada. Así, en la encíclica Etsi iam diu, del 24 de septiembre de 1824, los hispanoamericanos fueron nuevamente instados a la «defensa de la religión y de la potestad legítima», lo que propició que en este continente se levantaran voces para señalar que sencilla y definitivamente el Papa no tenía jurisdicción sobre este tipo de asuntos de índole temporal. ${ }^{73}$

\section{LA «CUESTIÓN ROMANA», EL REGALISMO Y LA AUTONOMÍA DEL EPISCOPADO}

En las monarquías católicas que no se separaron de Roma, tras la Reforma protestante, el absolutismo pretendió un nivel de independencia respecto al papado, para lo cual acentuó una política regalista con la consiguiente intervención en los asuntos de jurisdicción eclesiástica: nominación de obispos, creación de parroquias y recolección de diezmos, entre otros. En todo caso, ya el Patronato logrado por

\footnotetext{
71 Torres y Peña [1814]: 32 y 33.

72 Ibídem: 34.

73 Lynch 2012: 167-170.
} 
la corona española en 1508, llegó a configurar una institución de carácter regalista, que le permitió ejercer una marcada injerencia en la administración de la Iglesia americana. En el siglo de las Luces, con la llegada de la casa de Borbón al trono de España se impuso una autonomía aún mayor respecto a Roma, que se reflejó en el auspicio de un episcopado formado y comprometido con el espíritu galicano importado de Francia, acorde con el despotismo ilustrado, y con las medidas encaminadas a someter todas las estructuras e instancias del poder. De esta forma, cuando Carlos III Ilegó al trono, ya el Patronato universal había sido otorgado a los monarcas españoles sobre todos sus dominios. En 1765, el rey se declaró «Vicario y Delegado de la Silla Apostólica, con pleno derecho para intervenir en el gobierno espiritual de las Indias». ${ }^{74}$ Este regalismo borbónico vino acompañado de la implementación de costumbres galicanas que procuraban incrementar la autonomía del episcopado español frente al Papa. ${ }^{75}$ Este tipo de regalismo, junto con el conciliarismo, eran claramente afines con los planteamientos del tardojansenismo propuestos en el Sínodo de Pistoya (1786), que respondían a las aspiraciones de ciertos sectores de la Ilustración católica en España, orientadas al fortalecimiento de una Iglesia nacional. ${ }^{76}$

Frente a este tipo de políticas fomentadas por los Borbones podemos distinguir las siguientes posturas. La primera, de acomodamiento por parte de la alta jerarquía, especialmente de los obispos que debían sus cargos a la intervención monárquica. Esta fue la actitud de la mayor parte del episcopado en la América española. Otra, estuvo representada por buena parte del bajo clero, crítico del absolutismo, de la teoría del Derecho Divino y del Vicariato, vistos como un intento de "sacralización regia»; 77 asimismo romanista y, por tanto, inconforme con lo que interpretaba como una abusiva intromisión de la corona en los asuntos eclesiásticos, en la comunicación entre el Papa y la Iglesia en las Indias; y con las pérdidas económicas que representaban para la Iglesia, en general, y el bajo clero, en particular, las disposiciones tomadas por los Borbones en esta materia; ${ }^{78}$ política que luego, tras la invasión napoleónica, la Junta Suprema quiso mantener, lo que dio pie al reclamo del neogranadino Fernando Cayzedo y Flórez, quien solicitó la derogación del pago de tales prebendas que arruinaban a la Iglesia y lesionaban sus tradicionales derechos. ${ }^{79}$

\footnotetext{
74 Hera 1992: 393-409.

75 Smith 2010: 25-27.

76 Dichos postulados tardojansenistas impulsaron el episcopalismo y la autonomía jurisdiccional de los párrocos, a la vez que enfatizaron en que el Papa era únicamente la cabeza ministerial de la Iglesia; mientras que el rey era el encargado de promover las asambleas eclesiásticas y de otorgar el exequátur, así como de intervenir en ciertas regulaciones concernientes al sacramento del matrimonio (Saranyana 2010: 60).

77 Lazcano 2010: 28, en Miguélez.

78 Además de la impopular expulsión de los jesuitas, en 1767, hubo otra medida que tuvo su razón de ser en la grave situación financiera de la monarquía derivada de su alianza con Napoleón: la consolidación de vales reales de 1804 fue una desamortización que, como tal, supuso la enajenación de una gran parte de los capitales de las instituciones eclesiásticas y las obras pías, lo que tuvo un efecto devastador especialmente sobre las condiciones de sustento del bajo clero. En el virreinato de la Nueva Granada, en poco menos de dos años se remataron fincas por casi medio millón de pesos (Wobeser 2002: 787827; González 1997: 104).

79 Saranyana y Alejos Grau 2008: 246-247.
}

En este sentido, es claro que había sectores del catolicismo americano de principios del siglo XIX, para los que el panorama europeo mostraba a una Santa Sede asediada por el anticlericalismo revolucionario, los atropellos de Napoleón y las medidas por él adoptadas en el Código que lleva su nombre, tales como la abolición del celibato sacerdotal y la implantación del matrimonio civil. Y, en el mejor de los casos, aún las monarquías católicas cometían excesos, con sus costumbres regalistas y conciliaristas, como era el caso de la dinastía borbónica en España e Indias. De dicho descontento brinda inspirado testimonio el presbítero Mariano del Campo y Larraondo, quien esbozó, en verso, lo que pudo llegar a parecer una inusitada propuesta:

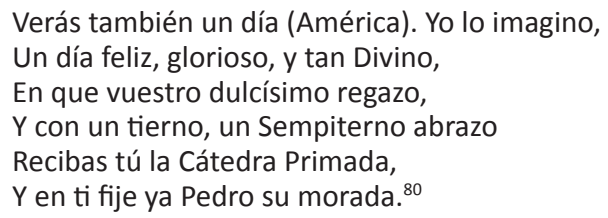

Así, el sacerdote payanés sugirió la posibilidad de que el papado se instalara en América, donde la lealtad de los católicos pondría al romano pontífice a salvo de los errores y abusos que vivía la Iglesia en Europa; y donde - según creía el padre Mariano del Campo y Larraondo- el gobierno civil y la libertad de las nuevas repúblicas no estarían por encima de la religión -como sí ocurría bajo el regalismo de la monarquía española- ni atentaría contra sus tradicionales fueros. En este sentido, la bandera de la guerra de independencia en Nueva Granada fue para una buena parte del clero y de los laicos católicos, romanista, en cuanto fue antiabsolutista y contraria al regalismo, así como también opuesta a un tipo de liberalismo anticlerical y secularizante.

\section{CONCLUSIONES}

El sustrato político-teológico del ámbito hispánico se reflejó, durante la independencia de la Nueva Granada, en un conjunto de ideas que abarcó: un sentido de la historia -la Providencialista-; un concepto común sobre el origen religioso del poder y el consiguiente deber de obediencia; así como un consenso sobre los criterios éticos de gobierno y justicia: el respeto a la ley divina y natural, la búsqueda de la salvación y del bien común; y el desconocimiento o reconocimiento del derecho de resistencia. Frente al pensamiento cristiano tradicional pactista y a un tipo de Ilustración liberal heredera de la neoescolástica - tanto en la concepción política como en su actitud romanista - se opuso una interpretación heterodoxa y absolutista del poder que, aunque no desvinculó a la monarquía de sus deberes tradicionales, sí limitó el derecho de resistencia y rebelión de los súbditos, así como también se mostró favorecedora del regalismo. Es importante tener en cuenta que dicho absolutismo suscitó descontento y una serie de protestas en todo el ámbito cristiano -incluido el protestante- a lo largo de la Edad Moderna. Entre ellas, precisamente, las revoluciones de independencia de Estados Unidos e Hispanoamérica. Cabe recordar que incluso los constituyentes de Cádiz, en 1812, manifestaron su primordial interés en recuperar -con

\footnotetext{
80 Campo y Larraondo 2012: 127-128.
} 
soluciones acordes con los tiempos - los antiguos derechos perdidos con el absolutismo. Así, «los liberales invocaban la tradición para destruir el Antiguo Régimen». ${ }^{81}$

Por lo tanto, en el ámbito hispánico, la llustración reelaboró un tipo de síntesis, en clave liberal, del tradicional pensamiento político cristiano. Acerca de estas continuidades y discontinuidades, resulta indispensable retomar los aportes de la historiografía colombiana. A mediados del siglo XX, el constitucionalista húngaro radicado en Colombia, Leopoldo Uprimny; y en la década de los sesenta y setenta, el sacerdote Rafael Gómez Hoyos, no solo resaltaron el peso de la neoescolástica en la independencia, sino la forma como sus postulados fueron posteriormente reinterpretados por los filósofos de las Luces, en varios aspectos, entre ellos, la soberanía popular, el contractualismo y la transferencia del poder.

Por consiguiente, ante la controversia sobre el peso de la neoescolástica y la llustración, antes que preferir una solución dicotómica, optamos por el planteamiento integrador de Francisco-Xavier Guerra, quien concluyó que, en el curso de las revoluciones de independencia, las naciones hispanoamericanas accedieron a la modernidad a partir del pensamiento populista, pero "reinterpretado por los ilustrados desde el iusnaturalismo racionalista moderno. ${ }^{82} \mathrm{~A}$ conclusiones afines llegaron los discípulos de Guerra, Clément Thibaud y María Teresa Calderón, cuando propusieron que la modernidad en Hispanoamérica no se agotó con el guión del liberalismo ilustrado, sino que, por el contrario, presenta características propias, solo comprensibles si se tienen en cuenta el peso del pensamiento y las tradiciones políticoteológicas del Antiguo Régimen. Creemos, por nuestra parte, que estas interpretaciones - primero de Uprimny y Gómez Hoyos, y luego, de Guerra, Thibaud y Calderónpermiten rescatar el importante papel del mundo hispánico, y más concretamente del pensamiento tradicional cristiano, en la invención de la modernidad política.

Es importante reiterar que la independencia y la naciente institucionalidad republicana se nutrieron de una versión ilustrada afín con la neoescolástica católica. Si bien hubo nostalgia respecto a algunos de los tradicionales deberes de la monarquía y de los derechos de representación de los vasallos, la solución contractual moderna (Locke, Rousseau) fue criticada en el ámbito hispánico por figuras como las de Feijoo y Jovellanos; y asimilada, tras una reinterpretación coherente con el pactismo tradicional. ${ }^{83}$

Así, aunque el ideario pactista sirvió para justificar la independencia, durante este proceso emergió, especialmente entre las élites intelectuales y políticas más jóvenes e ilustradas, una concepción de la sociedad y la política acorde con las sociabilidades y el pensamiento moderno, que seguramente estaba latente y que, irónicamente, en buena parte se formó bajo el auspicio del despotismo ilustrado, como actor y gestor de la modernidad. De esta forma, la «restauración» de los derechos desconocidos por la modernidad absolutista, se efectuó a partir de otra versión política de la modernidad católica, esta vez en clave liberal. ${ }^{84}$ Ejemplo de ello es el sacerdote neogranadino

\footnotetext{
81 Pérez 2014: 403.

82 Amores 2011: 8.

83 Guerra 1992: 170. Fernández de Sarasola 2012: 103-168.

84 Ibídem: 175.
}

Diego Padilla, quien, según Saranyana, «se hallaba situado entre dos mundos, anhelando la novedad, pero sin perder pie en la tradición». ${ }^{85}$ Por lo tanto, las constituciones de las nacientes repúblicas en las que subyace el reconocimiento del origen divino del poder y plasman el confesionalismo, igualmente defendieron los derechos del individuo $-\mathrm{y}$ no de las corporaciones-, promulgaron la igualdad de los ciudadanos; y estructuraron el Estado a partir de la división de poderes públicos. Se trata, obviamente, de un tipo de concepción ilustrada y liberal católica, que en sus presupuestos político-religiosos no riñe con la neoescolástica.

En este sentido, subrayamos el hecho de que quienes defendieron o se opusieron a la independencia, en el ámbito social configurado por la "república de las letras», ${ }^{86}$ fueron ilustrados católicos que, en términos generales, mantuvieron su creencia en la fuente divina del poder. Así, la defensa de la monarquía se hizo desde el despotismo ilustrado y, por ende, desde la teoría del Derecho Divino y el concepto de maiestas. Pero, sobre todo, a partir del criterio común y tradicional de "gobierno según justicia», que, como ya vimos, también esgrimieron los independentistas. Por otra parte, entre estos últimos, estaban quienes tenían la esperanza de que en la nueva república serían respetados los tradicionales derechos de Roma, incluso más que bajo el gobierno de la regalista monarquía española.

En cuanto a las posibles repercusiones del tardojansenismo en la independencia, es necesario recordar que el Sínodo de Pistoya presentó en sus decretos una reflexión teórica que dio legitimidad al regalismo borbónico y a la actitud antirromana. Por lo pronto, lo que resulta evidente, para el caso de Nueva Granada, es precisamente que el regalismo de la corona, las tendencias conciliaristas, auspiciadas por la influencia del jansenismo, así como las disposiciones contra los fueros y bienes tradicionales de la Iglesia, estuvieron entre los principales motivos de descontento de un sector católico americano; especialmente identificable en el bajo clero y entre los próceres de la primera generación, muchos de ellos desaparecidos bajo la cruel Pacificación de Pablo Morillo.

Por otra parte, al retomar la idea de la posible influencia del conciliarismo en el virreinato habría primero que mencionar que ciertas prácticas heterodoxas fueron llevadas a cabo, en 1811, en la Villa del Socorro, donde se instituyó una nueva sede episcopal y el canónigo Andrés Rosillo fue proclamado obispo, por aclamación popular. Como justificación, los abogados Ignacio Herrera y Manuel Plata citaron al autor jansenista Zeger Bernard Van Espen. ${ }^{87}$ No obstante, la reacción contraria no se hizo esperar. Pronto se realizó un Congreso Supremo y General del Clero de las Provincias Unidas de la Nueva Granada para condenar dicho proceder. ${ }^{88}$ Lo que nos lleva a pensar que, en la conciencia general de los católicos neogranadinos, este tipo de iniciativas eran objeto de rechazo; y lo ocurrido en el Socorro obedeció más a circunstancias coyunturales que a serias y extendidas convicciones teológicas de corte jansenista. Además, entre los argumentos de los socorranos, para justificar su decisión, estaba el ejercicio de la prerrogativa del Patronato, tras la

\footnotetext{
85 Saranyana y Alejos Grau 2008: 242.

86 Guerra 1992: 98-102.

87 Mestre 2003, cit. por Calderón y Thibaud 2010: 132.

88 Sanz-Díaz 1978: 229.
} 
legítima reasunción de la soberanía por parte del pueblo, tesis, esta última, de corte tradicional. ${ }^{89}$ No obstante, las justificaciones jansenistas no solo demuestran el conocimiento de ellas en la Nueva Granada, sino su posible, eventual e incipiente aceptación, en cuanto a la autonomía del poder civil y la independencia del episcopado respecto a la Santa Sede.

En este orden de ideas y como ya se ha dicho, no debe extrañar el hecho de que si bien las primeras constituciones durante la Patria Boba proclamaron los principios liberales, asimismo reconocieron el catolicismo como religión de Estado, reclamaron el Patronato y anunciaron la defensa de la Iglesia..$^{90}$ Este último aspecto debió tranquilizar al clero rebelde que creyó ver resguardados los derechos de aquella bajo los nuevos gobiernos - eso sí, ahora en un clima de mayor tolerancia, lo que pronto conduciría a la implementación de medidas como la supresión del tribunal de la Inquisición-. Aquí es importante aclarar que si bien a los revolucionarios de la primera generación y a buena parte del clero, les resultaba odioso el regalismo borbónico -o por lo menos, algunas de sus manifestaciones-; es claro que, por otro lado, los jóvenes próceres de la segunda generación, triunfantes militares que asumieron el gobierno de las nuevas repúblicas, algunos de ellos menos comprometidos por sus convicciones personales en materia religiosa, vieron antes que nada la importancia instrumental de la Iglesia a favor del nuevo gobierno; y, en este sentido, aspiraron al ejercicio reforzado del Patronato y a la libertad de cultos.

El nivel de injerencia del Estado en los asuntos eclesiásticos y el grado de autonomía de las dos potestades, sería materia de álgido debate a lo largo de la historia republicana del siglo XIX colombiano. En dicho siglo, el partido conservador prolongó la corriente del liberalismo católico que prevaleció durante la Patria Boba; es decir, un liberalismo confesionalmente católico, romanista, con una formal separación de potestades, en mutua colaboración, aunque con aspiraciones de moderada y recíproca intervención, en términos aceptables para el clero. Mientras que el partido liberal siguió lineamientos más autónomos respecto a Roma, defendió la libertad de cultos, pero, sobre todo, se mostró más abiertamente inclinado al sometimiento de la Iglesia a los intereses públicos, como ocurrió, por ejemplo, con Bolívar y Santander, en los inicios de la Gran Colombia; y luego, con mayor énfasis, bajo la República Radical (1861-85), cuando el anticlericalismo alcanzó su máxima expresión, sin que la mayoría de los liberales dejaran de reconocerse como católicos. Este debate entre las distintas formas de liberalismo católico y su posición respecto a la "cuestión religiosa», es decir, acerca de las relaciones Iglesia-Estado, se extendió a lo largo del siglo XIX y parte del $X X$, dando lugar a diversos matices e interpretaciones que, en su momento, fueron fundamento del sustrato político ideológico de los partidos tradicionales, el liberal y el conservador - así como de las distintas corrientes al interior de ellos-, y de sus luchas durante un prolongado lapso de tiempo de la historia nacional.

89 Saranyana y Alejos Grau 2008: 270-271.

90 Archivo Histórico Cipriano Rodríguez Santamaría, Breve discurso sobre la libertad de cultos que dirige al Congreso Constituyente de Colombia el Presbítero Dr. Mariano del Campo y Larraondo, 1830, CO-CH-US-AHCRS-MMM-1.5.1.3. R1, Caja 38, Carpeta 4, ff. 288-293.

\section{BiBLIOgRAFÍA}

Amores Carredano, J. B. 2011. “"Gobernar según justicia”. Realistas y patriotas en Nueva Granada: 1810-1816», en J. I. Saranyana y J. B. Amores (eds.), Política y religión en la independencia de Nueva Granada: 131-152. Madrid: BAC.

Arce Escobar, V. 2012. "La Biblia como fuente de reflexión política en los sermones neogranadinos, 1808-1821». CS Ciencias Sociales 9: 273-307. https://doi.org/10.18046/recs.i9.1223

Artuñano Aldea, S. 2010. San Agustín: La Ciudad de Dios, edición, estudio preliminar, selección de textos, notas y síntesis. Madrid: Tecnos.

Bernardo de Claraval, Santo 2005. «Elogio de la nueva milicia templaria», en R. Pernoud (ed.), Los Templarios: 39-79. Madrid: Siruela.

Bossuet, J. B. 1789. Política deducida de las propias palabras de la Sagrada Escritura, dirigida al Serenísimo Señor Delfín: I. Madrid: Imprenta de Don Pedro Marín.

Calderón, M. T. y Thibaud, C. 2010. La majestad de los pueblos en la Nueva Granada y Venezuela, 1780-1832. Bogotá: Taurus, Universidad Externado de Colombia.

Campo y Larraondo, M. del 2012. Rasgos poéticos que pueden servir de apuntamientos sobre la historia de nuestra revolución escritos por el doctor Mariano del Campo y Larraondo, transcripción y comentarios de M. Revollo Rueda. Chía: Universidad de La Sabana.

Capánaga, V. 1994. "La ciudad de Dios o la dialéctica de la historia», en V. Capánaga (ed.), Obras completas de San Agustín, I: 234-258. Madrid: BAC.

Carvajal, P. 2000. «El derecho de resistencia en la teología política de Juan Calvino». Revista de Estudios Histórico-Jurídicos 22: 335-351. https://doi.org/10.4067/s0716-54552000002200015

Colegio Revisor y Electoral. 1812. Constitución de la República de Cundinamarca reformada por el Serenísimo Colegio Revisor y Electoral. Santafé de Bogotá: Bruno Espinosa de los Monteros por D. Nicomedes Lora.

Cortés, J. D. 2010. «La lealtad al monarca español en el discurso político religioso en el Nuevo Reino de Granada». Anuario Colombiano de Historia Social y de la Cultura 37: 43-83.

Demélas-Bohy, M. D. 2002. "La guerra religiosa como modelo», en F. X. Guerra (dir.), Revoluciones hispánicas, independencias americanas y liberalismo español: 143-164. Madrid: Editorial Complutense.

Feijoo, B. J. 1773. "Carta 19. Sobre el nuevo arte del beneficio de la plata», en Cartas eruditas, y curiosas, En que, por mayor parte se continúa el designio del Theatro Crítico Universal, impugnando ó reduciendo á dudosas, varias opiniones comunes: II/257-262. Madrid: Imprenta Real de la Gazeta, a costa de la Real Compañía de Impresores y Libreros.

Fernández Álvarez, M. 2006. Carlos V, el César y el hombre. Madrid: Espasa, Fundación Europea de Yuste.

Fernández de Sarasola, I. 2012. "La dimensión política de Jovellanos», en AA.VV, Jovellanos: el hombre que soñó España: 103-168. Madrid: Encuentro.

Fernández de Sotomayor, J. 1815. Sermón que en la solemne festividad del 20 de julio aniversario de la libertad de la Nueva Granada publicó en la Iglesia Metropolitana de Santafé el ciudadano Juan Fernández de Sotomayor, Representante en el Congreso de las Provincias Unidas por la de Cartagena y en ese Obispado Cura Rector y Vicario Juez Eclesiástico de la Ciudad Valerosa de Mompox. Santafé de Bogotá. Imprenta del C.B. Espinosa, por el C. Nicomedes Lora.

Fernández de Sotomayor, J. 1820. Catecismo o instrucción popular por el C. Dr. Juan Fernández de Sotomayor Cura Rector y Vicario Juez Eclesiástico de la valerosa ciudad de Mompox. Santafé de Bogotá: Reimpresión en la Imprenta de C. B. E.

Finestrad, J. de 2001. El vasallo instruido en el estado del Nuevo Reyno de Granada y en sus respectivas obligaciones, transcripción e introducción de M. González. Bogotá: Universidad Nacional de Colombia.

Font Oporto, P. 2013. «El núcleo de la doctrina de Francisco sobre la resistencia y el tiranicidio». Pensamiento 69/260: 493-521.

Gómez Hoyos, R. 1962. La Revolución Granadina de 1810: ideario de una generación y de una época, 1781-1821. Bogotá: Temis. 
González, F. 1997. Poderes Enfrentados: Iglesia y Estado en Colombia. Bogotá: Cinep.

Guerra, F. X. 1992. Modernidad e independencias. Madrid: Mapfre.

Guerra, F. X. 2012. "“Políticas sacadas de las Sagradas Escrituras", la referencia a la Biblia en el debate político», en $\mathrm{A}$. Lampiérière y $\mathrm{G}$. Lomné, Figuras de la Modernidad hispanoamericana. Siglos XIX y XX: 231-287. Bogotá: Universidad Externando de Colombia, Taurus.

Hera, A. de la 1992. Iglesia y Corona en la América española. Madrid: Mapfre.

Jaramillo Uribe, Jaime. 1994. «El conflicto entre la conciencia religiosa y la ciencia moderna: Mutis y Caldas», en La personalidad histórica de Colombia y otros ensayos: 72-98. Bogotá: Áncora.

Lazcano, R. (edición, prólogo, notas e índice). 2010 «Prólogo», en M. Fraile Miguélez, Jansenismo y Regalismo en España (Datos para la historia). Cartas al Sr. Menéndez Pelayo: 9-45. Madrid: Editorial Agustiniana, Guadarrama.

León, A. de 1816. Discurso político moral: sobre la obediencia debida a los reyes, y males infinitos de la insurrección de los pueblos. Santafé de Bogotá: Bruno Espinosa.

Lynch, J. 2012. Dios en el Nuevo Mundo: una historia religiosa de América Latina. Barcelona: Crítica.

Mariana, J. de 1950. Del Rey y de la institución real: XXXI/ I. Madrid: BAC.

Martínez de Codes, R. M. 1992. La Iglesia católica en la América independiente, siglo XIX. Madrid: Mapfre.

Mestre Sanchis, Antonio. 2003. "La influencia del pensamiento de Van Espen en la España del siglo XVIII», en Apología y crítica en el siglo XVIII: 289-319. Madrid: Marcial Pons Historia.

Nariño, A. 1811. Suplemento a la Bagatela 5. Santafé de Bogotá: Bruno Espinosa de los Monteros.

Ocampo López, J. 1999. El proceso ideológico de la emancipación en Colombia. Bogotá: Planeta.

Olano García, H. A. 2014. «El derecho eclesiástico del Estado colombiano de 1811 a $1991 »$. Hispania Sacra LXVI: 421-455. https://doi.org/10.3989/hs.2014.095

Padilla, D. F. 1811. Diálogo entre un cura y un feligrés del pueblo de Boxacá sobre el párrafo inserto en la Gazeta de Caracas. Sobre la Tolerancia. Santafé de Bogotá: Bruno Espinosa.

Pérez, J. 2014. Historia de España. Barcelona: Crítica, Planeta.

Santa Cruz, A. de 1920-1925. Crónica del Emperador Carlos V: I. Madrid: ed. Blázquez y Beltrán.

Sanz-Díaz, J. 1978. «El maranchonero D. Juan Bautista Sacristán y Martínez Atance vigésimo arzobispo de Santa Fe de Bogotá». Revista de Estudios de Guadalajara 5: 219-236.

Saranyana, J. I. 2010. «La eclesiología de la revolución en el Sínodo de Pistoya (1786)». Anuario de Historia de la Iglesia 19: 55-71.

Saranyana, J. I. 2011. «Política y religión en la insurgencia americana. Conclusiones generales», en J. I. Saranyana y J. B. Amores (eds.),
Política y religión en la independencia de la América hispana: 229239. Madrid: BAC.

Saranyana, J. I. (dir.) y Alejos Grau, C. J. (coord.) 2005. Teología en América Latina: Escolástica barroca Ilustración y preparación de la Independencia (1665-1810): II/1. Madrid: Iberoamericana.

Saranyana J. I. (dir.) y Alejos Grau, C. J. (coord.) 2008. Teología en América Latina: Escolástica barroca Ilustración y preparación de la Independencia (1665-1810): II/2. Madrid: Iberoamericana.

Silva, R. 2005. «La teoría del poder divino de los reyes en el virreinato de la Nueva Granada», en La llustración en el virreinato de la Nueva Granada. Estudios de historia social. Medellín: La Carreta.

Smith, A. J. 2010. «Bourbon Regalism and the Importation of Gallicanism: The Political Path for a State Religion in EigteenthCentury Spain». Anuario de Historia de la Iglesia 9: 25-53.

Suárez, F. 1970. Defensa de la fe. Madrid: Instituto de Estudios Políticos. Tomás de Aquino, Santo 1960. «De la Sedición», en F. Barbado Viejo (ed.), Suma Teológica, VII: 1089-1093. Madrid: BAC.

Torres y Peña, J. A. de 1960 [1808]. «Expresión de los sentimientos de la religión y el patriotismo, Que en la fiesta de acción de gracias por la proclamación que hizo el Cabildo Justicia y Regimiento de la muy noble y leal ciudad de Santafé de Bogotá, capital del Nuevo Reyno de Granada, por nuestro católico Monarca el Señor don Fernando Séptimo Rey de España e Indias. Pronunció D. José Antonio Torres y Peña, cura doctrinero de Enemocón Pueblo de la Real Corona, de la jurisdicción del mismo Cabildo. Con las licencias necesarias. Reimpreso en la Patriótica de Santafé de Bogotá, Calle de los Carneros, Año de 1808», en G. Hernández de Alba (transcripción, prólogo y notas), Memorias sobre los orígenes de la independencia nacional: 163-183. Bogotá: Kelly.

Torres y Peña, J. A. de 1960 [1814]. «Memorias sobre la revolución y sucesos de Santafé de Bogotá, en el trastorno de la Nueva Granada y Venezuela, 1814», en G. Hernández de Alba (transcripción prólogo y notas), Memorias sobre los orígenes de la independencia nacional: 27-135. Bogotá: Kelly.

Uprimny, L. 1952-1954. «Capitalismo calvinista o romanticismo semiescolástico de los próceres de la Independencia colombiana: réplica al profesor Alfonso López Michelsen». Revista Javeriana 3, 4, 5 y $6: 135-149,147-175,113-153,87-148$.

Vitoria, F. de 1928. Relecciones sobre los indios y el derecho de guerra: con trozos de la referente a la potestad civil. Madrid: Espasa-Calpe.

Vitoria, F. de 1995. "Lectura 137. Si los preceptos judiciales fueron dados convenientemente con relación a la convivencia de los pueblos», en L. Frayle Delgado (Estudio preliminar y traducción), La Ley: 129-135. Madrid: Tecnos.

Wobeser, G. von 2002. "Gestación y contenido del real decreto de consolidación de vales reales para América». Historia Mexicana LXI (4): 787-827. 